\title{
Reversal effect of Ganoderma lucidum polysaccharide on multidrug re- sistance in K562/ADM cell line ${ }^{1}$
}

\author{
Wei-dong $\mathrm{LI}^{2,4}$, Bo-di ZHANG ${ }^{2}$, Ran WEI' ${ }^{2}$ Ji-hong LIU ${ }^{3}$, Zhi-bin LIN $^{2}$ \\ ${ }^{2}$ Department of Pharmacology, School of Basic Medical Sciences, Peking University Health Science Center, Beijing 100083, China; ${ }^{3}$ Confo- \\ cal Microscope Laboratory, Peking University Health Science Center, Beijing 100083, China
}

\section{Key words}

multidrug resistance; Ganoderma lucidum polysaccharides; K562/adriamycin; Pglycoprotein; multidrug resistance-1; multidrug resistance-associated protein-1

\footnotetext{
${ }^{1}$ This research was supported by a research fund from Shanghai Green Valley Holding. ${ }^{4}$ Correspondence to Prof Wei-dong LI.

Phn 86-10-8280-2798.

Fax 86-10-8280-1686.

E-mail 1wdpharma@126.com
}

Received 2007-10-18

Accepted 2007-12-18

doi: $10.1111 / \mathrm{j} .1745-7254.2008 .00776 . x$

\begin{abstract}
Aim: To investigate the reversal effect of Ganoderma lucidum polysaccharides ( $G l$-PS) on multidrug resistance (MDR) in the adriamycin (ADM)-resistant leukemic cell line K562/ADM. Methods: Cytotoxicity was assayed by 3-(4,5-dimethylthiazol2-yl)-2,5-diphenyltetrazolium bromide method; the ADM concentration in cells was determined by flow cytometry and confocal laser scanning microscopy techniques; the expression of P-glycoprotein was assayed by flow cytometry; and the mRNA expression levels of MDR-1 and MDR-associated protein (MRP)1 were determined by RT-PCR. Results: $G l$-PS reversed MDR in K562/ADM cells. $G l$-PS obviously reversed the resistance of K562/ADM to doxorubicin. The reversing factors of $G l$-PS at 10 and $20 \mathrm{mg} / \mathrm{L}$ were 6.46 and 6.80, respectively. MDR-1 and MRP1 transcription were downregulated by 10 and $50 \mathrm{mg} / \mathrm{L}$ Gl-PS. Conclusion: Gl-PS can reverse the MDR by downregulating the expression of MDR-1 and MRP1 in K562/ADM cells.
\end{abstract}

\section{Introduction}

Multidrug resistance (MDR), a major cause of cancer treatment failure, is a phenomenon whereby cancer cells develop resistance to a wide variety of chemotherapeutic drugs. MDR has been associated with the overexpression of P-glycoprotein (P-gp) or MDR-associated protein (MRP), 2 transmembrane transporters that act as pumps to remove toxic drugs from tumor cells. The MDR-1 overexpression has been reported in many tumors and in vitro-selected, drug-resistant cell lines ${ }^{[1-4]}$. Meanwhile, MRP1 has also been identified as having the ability to induce MDR. It has been found that the accumulation of chemotherapeutic agents in tumor cells with overexpressed P-gp170 or MRP1 was significantly reduced as compared to the MDR antagonist-treated tumor cells $^{[5-7]}$. The other approach for MDR regulation is the modulation of the MDR-1 gene. Studies on the MDR-1 gene promoter suggest that the inhibition of the $\mathrm{P}$-gp expression may occur at the gene level ${ }^{[8]}$. The MDR modulators may either block the induction of MDR-1 or MRP1 gene expression or downregulate P-gp expression. Up to now, there have been many drugs used to decrease the incidence of MDR clinically. Unfortunately, the drugs, such as verapamil (VER) ${ }^{[9]}$, have distinct toxicity at MDR treatment concentrations, so their clinical treatments are restricted. It is necessary to find more effective and less toxic drugs that can be used for cancer therapy.

Ganoderma lucidum (Gl; Lingzhi) is a traditional Chinese medicine and has been widely used in China and other Oriental countries to prevent and treat various diseases for a long time. $G l$ polysaccharides ( $G l$-PS) are the main pharmacological ingredient extracted from the fruit body and mycelium of mushroom $G l$ (Fr) Karst. A lot of experimental evidence has been accumulated in the past several decades, and the data suggest that $G l$-PS have wide activities, such as immune modulation, and antitumor ${ }^{[10,11]}$, anti-atherosclerosis, antidiabetic, and anti-aging activities ${ }^{[12]}$.

$G l$ is possibly effective in cancer patients receiving conventional chemotherapy. Recently, investigators have focused attention on the effect of Gl-PS on antitumor and immunologic regulation. The water extract and the polysaccharide fraction of $G l$ showed significant antitumor effects in several tumor-bearing animals, mainly through its immunoenhancing activity. Recent studies also showed that the alcohol extract or the triterpene fraction of $G l$ also had 
antitumor effects, which may be directly related to the cytotoxic activity against tumor cells ${ }^{[13-20]}$. So far, it is not clear whether Gl-PS have effects on conversing MDR. The purpose of this study is to investigate the effects of $G l$-PS on MDR and the influence on the gene expression of MDR-1 and MRP1 in human K562/adriamycin (ADM) cells.

\section{Materials and methods}

Reagents and drugs $G l$-PS were extracted from the fruit body of $G l$ (Leyss ex Fr) Karst by boiling water, followed by ethanol precipitation, dialysis, and protein depletion. $G l$ contains polysaccharide peptides with a molecular weight of 584900 ; the ratio of polysaccharides to peptides is $93.51 \%: 6.49 \%$. The polysaccharides consisted of $D$ hamnose, $D$-xylose, $D$-fructose, $D$-galactose, $D$-mannose, and $D$-glucose with a molar ratio of 0.793:0.964:2.944:0.167:0. 389:7.94 and linked together by b-glycosidic linkages. The peptides contained 16 kinds of amino acids. RPMI-1640 medium was purchased from Gibco (Grand Island, NY, USA). 3(4,5-Dimethylthiazol-2-yl)-2,5-diphenyltetrazolium bromide (MTT) and DMSO were purchased from Sigma (St Louis, MO, USA). ADM and VER were purchased from PRC Navy General Hospital (Beijing, China), and the P-gp monoclonal antibody was purchased from Santa Cruz (Santa Cruz, CA, USA). Total RNA isolation kits and one-step RT-PCR kits were purchased from SBS (Beijing, China).

Cell lines The K562 cell line (drug sensitive) was a generous gift from Prof Wen-jie WANG (Institute of Materia Medica, Chinese Academy of Medical Science, Beijing, China), and the multidrug cell line K562/ADM was purchased from the Chinese Medicine Academy (Beijing, China). These 2 cell lines were seeded in RPMI-1640 with $15 \%$ newborn bovine serum. K562/ADM was treated with ADM 2 weeks before the experiment. The cells in all of the experiments were gathered when they were in the exponential growth phrase.

Measurement of cytotoxicity by MTT method The cells were incubated in 96-well plates $\left(1.0 \times 10^{5} /\right.$ well $)$, in $100 \mu \mathrm{L}$ medium. ADM and $G l$-PS were added at different concentrations ( $G l$-PS: 5, 10, 20, and $40 \mathrm{mg} / \mathrm{L}$ ). VER was added as a positive control. After $44 \mathrm{~h}$ incubation at $37^{\circ} \mathrm{C}, 20 \mu \mathrm{L}$ MTT ( $5 \mathrm{~g} / \mathrm{L}$ in phosphate-buffered saline [PBS]) was added. The plates were incubated for $4 \mathrm{~h}$, and the blue dye was dissolved in $100 \mu \mathrm{L}$ DMSO. The absorbance at $570 \mathrm{~nm}$ was determined using an ELISA multiscan reader ${ }^{[21]}$.

The survival rate of the cells was calculated as follows: Survival rate $(\%)=(\mathrm{T}-\mathrm{B}) /(\mathrm{U}-\mathrm{B}) \times 100 \%$,

where $\mathrm{T}$ represents treated: the absorbance of tumor cells exposed to drugs; $\mathrm{U}$ is untreated: the absorbance of un- treated cells; B is blank: the absorbance of cells without drugs and MTT.

The $\mathrm{IC}_{50}$ for $\mathrm{ADM}$ in the $G l$-PS-treated or untreated tumor cells was determined, and the reversing factor (RF) was calculated as follows:

$\mathrm{RF}=\mathrm{IC}_{50}$ (control group)/ $\mathrm{IC}_{50}$ (drug-treated group).

Analysis of intracellular accumulation of ADM by confocal laser scanning microscopy The reversing effect of $G l$-PS was analyzed based on the inherent fluorescence of ADM, which accumulates in sensitive cells and is actively exported from cells expressing a functional P-gp and MRP1. The cells were maintained in medium for $48 \mathrm{~h}$ (K562/A cells were treated with 10 and $50 \mathrm{mg} / \mathrm{L} \mathrm{Gl}$-PS) prior to the ADM accumulation studies. The cells (100 000 cells/well) were seeded in chambered borosilicate cover glass slides (Nunc, Naperville, Ill) and incubated for $2 \mathrm{~h}\left(37^{\circ} \mathrm{C}\right.$, humidified $\left.5 \% \mathrm{CO}_{2}\right)$ to allow the cells to adhere to the chamber slides. Then ADM (10 mg/L) was added to the chamber slides. The chamber slides containing cells without drugs were used as negative controls. The cells were incubated with drugs for approximately $2 \mathrm{~h}$, washed once with Dulbecco's PBS, and examined immediately by confocal to quantitative intracellular fluorescence intensity. To determine the fluorescence intensities of ADM obtained by confocal microscopy from different treatments, excitation and detection parameters were kept constant. Correction for differences in optical thickness between the suspension analysis and intracellular ADM concentration was accomplished according to previously-described methods ${ }^{[22]}$. The laser cytometer was set at an excitation wavelength of $512 \mathrm{~nm}$, and the emitted fluorescence was detected with a barrier filter (band pass 530/30). Ten microscopic fields, each containing aggregates of 10-15 cells, were analyzed for each treatment. At least 2 experiments were performed on different days.

Flow cytometric analysis of intracellular accumulation of ADM The K562 and K562/ADM cells were separately seeded in $5 \mathrm{~mL}$ of medium at a density of $1 \times 10^{6}$ cells $/ \mathrm{mL}$. In total, $100 \mu \mathrm{L}$ drug solutions were added to obtain a final ADM concentration of $10 \mathrm{mg} / \mathrm{L}$ in the absence or presence of $10 \mathrm{mg} / \mathrm{L} \mathrm{Gl}$-PS. The cells were incubated at $37^{\circ} \mathrm{C}$ for $3 \mathrm{~h}$, by which time ADM accumulation had reached a steady state. Aliquots of cellular suspension were collected. The cells were immediately centrifuged for $10 \mathrm{~min}$ at $1000 \mathrm{r} / \mathrm{min}(153 \times \mathrm{g})$, and washed 3 times with cold PBS, and then the cell pellets were resuspended in PBS. The intensity of ADM was determined by the auto-fluorescence of ADM using FACS analysis ${ }^{[23]}$.

Flow cytometric analysis of P-gp The K562/ADM cells and $\mathrm{K} 562$ cells were plated at a density of $1 \times 10^{5}$ cell $/ \mathrm{mL}$ in RPMI-1640. At $24 \mathrm{~h}$ after plating, the medium was replaced 
with fresh medium containing 10 and $50 \mathrm{mg} / \mathrm{L}$ Gl-PS alone. After $24 \mathrm{~h}$, the cells were collected by trypsinization and adjusted to a density of $1 \times 10^{6}$ cells $/ \mathrm{mL}$ and centrifuged at $1000 \mathrm{r} / \mathrm{min}(153 \times g)$ for $8 \mathrm{~min}$ at $20^{\circ} \mathrm{C}$. The cell pellet was suspended in $20 \mu \mathrm{L}$ anti-P-gp antibody $\left(5 \mu \mathrm{L}\right.$ every $1 \times 10^{5}$ cells) and then incubated at $4{ }^{\circ} \mathrm{C}$ for $30 \mathrm{~min}$. After 2 washes with cold PBS containing $1 \%$ bovine serum albumin, the cells were incubated under protection from light at $4{ }^{\circ} \mathrm{C}$ for $30 \mathrm{~min}$ with fluorescein-isothiocyanate-conjugated goat antimouse immunoglobulin $\mathrm{G}(1: 100)$. Then the cells were centrifuged at $1000 \mathrm{r} / \mathrm{min}(153 \times \mathrm{g})$ for $10 \mathrm{~min}$ at $20^{\circ} \mathrm{C}$, and suspended in PBS. The fluorescence intensity in the cells was analyzed by the flow cytometer.

\section{RT-PCR assay for checking the mRNA level of MDR} andMRP

Isolation of total RNA The K562/ADM cells were seeded with $10 \mathrm{mg} / \mathrm{L} G l$-PS for $48 \mathrm{~h}$. Then $5 \times 10^{6}$ cells were collected. The total RNA isolation kits from SBS were used. All operations followed the protocol in the kit.

Determination of RNA quality and concentration The concentration and purity of total RNA was determined by UV light absorption using a GeneQuant pro RNA/DNA calculator (Biochrom, Cambridge, England). Preparations were discarded if they had a ratio of optical densities at $260 \mathrm{~nm} /$ $280 \mathrm{~nm}$ that was lower than $1.6^{[24]}$. To assess RNA quality, $5 \mu \mathrm{g}$ of total RNA from each sample was loaded onto $1 \%$ agaroseformaldehyde gels and subjected to electrophoresis. Following ethidium bromide staining, RNA isolates were considered good quality if the UV fluorescence of the 28S rRNA band intensity was 2-fold of the 18S rRNA band, and no UV fluorescence was detected below the 18S rRNA band.

Oligonucleotide PCR primers Sense and antisensespecific primers were synthesized at SBS. All primers were designed to span intron-exon boundaries to distinguish between the amplification of mRNA and genomic DNA, and were based on published human cDNA sequences.

cDNA synthesis and PCR All RT-PCR processes were performed by the one-step RT-PCR kits purchased from SBS. All operations followed the RT-PCR kit protocol. In total, $5 \mu \mathrm{g}$ total RNA from the K562/ADM cells treated with $\mathrm{Gl}$-PS at 10 and $50 \mathrm{mg} / \mathrm{mL}$ and the control were treated by using the following parameters: a reverse transcription step of $1 \mathrm{~h}$ at $42{ }^{\circ} \mathrm{C}$, an initial denaturing step of $10 \mathrm{~min}$ at $94^{\circ} \mathrm{C}$, denaturing at $94{ }^{\circ} \mathrm{C}$ for $1 \mathrm{~min}$, and annealing at $58^{\circ} \mathrm{C}$ for $50 \mathrm{~s}$, extending at $72{ }^{\circ} \mathrm{C}$ for $1 \mathrm{~min}$. The final polymerization step was extended for an additional $10 \mathrm{~min}$. In total, 32 cycles of PCR were performed. PCR amplification reactions were evaluated through electrophoresis on $1 \%$ agarose gels containing ethidium bromide and visualized by UV transillumination on a GeneGenius imager (Frederick, MD, USA). The initial product identification was made by comparison to the myometrial control and the molecular weight ladder, photographed by GeneGenius, and quantified by BandScan software (Beijing, China). All RT-PCR experiments were carried out at least 3 times.

\section{Statistical analysis}

Data are showed as mean \pm SEM from triplicate samples of 3 independent experiments. Differences between the means were analyzed by ANOVA. Results were considered to be statistically significant when $P<0.05$.

\section{Results}

Reversal effect of $G l$-PS on the multidrug K562/ADM cells To determine if $G l$-PS are toxic to normal cells, the effects of $G l$-PS on the K562 cells were assayed as described in Materials and methods. Figure 1 shows that $G l$-PS did not have significant cytotoxity on normal cells, but VER and $G l$-PS obviously reversed the resistance of K562/ADM to ADM. The RF were 2.96, 6.46, 6.80, and 3.35 in the 5, 10, 20, and 40 $\mathrm{mg} / \mathrm{L} \mathrm{Gl}$-PS-treatment groups, respectively (Figure 2). In the same condition, the RF of VER was 10.76. Both VER and Gl-PS did not change the $\mathrm{IC}_{50}$ of sensitive K562 cells. These results indicated that $G l$-PS can reverse the drug resistance of K562/ADM cells and enhance the cytotoxity of other antitumor drugs, such as ADM.

Effect of $G l$-PS on ADM accumulation in K562/ADM cells assayed by confocal laser scanning microscopy In order to examine whether $G l$-PS have a reversing effect on MDR, intracellular ADM accumulation was assessed by confocal laser scanning microscopy. Figure 3 shows the images of the fluorescence intensity representing intracellular ADM accumulation. Intracellular ADM accumulation in the K562/ ADM cells was significantly less than that that in the K562 cells. The distribution of ADM accumulation was also different between the K562 cells and K562/ADM cells. After treatment with $G l$-PS, ADM was distributed in the K562/ADM cells at higher concentrations than that in the K562 cells. We also found that in the K562 cells and K562/ADM plus Gl-PS, the $\mathrm{ADM}$ concentration was higher in nucleolus zones than in plasma, but not for K562/ADM cells. These results indicate that $G l$-PS can also downregulate the expression of MRP1.

Influence of $G l$-PS on ADM accumulation in K562/ADM cells determined by flow cytometric analysis The effect of $G l$-PS modulation on ADM efflux was also studied in resistant cells overexpressing P-gp and MRP1. Gl-PS were initially tested at 10 and $50 \mathrm{mg} / \mathrm{L}$. The $G l$-PS did not have inherent fluorescence and did not modulate ADM in the nonMDR-overexpressing K562 cells. Following the uptake of 
A

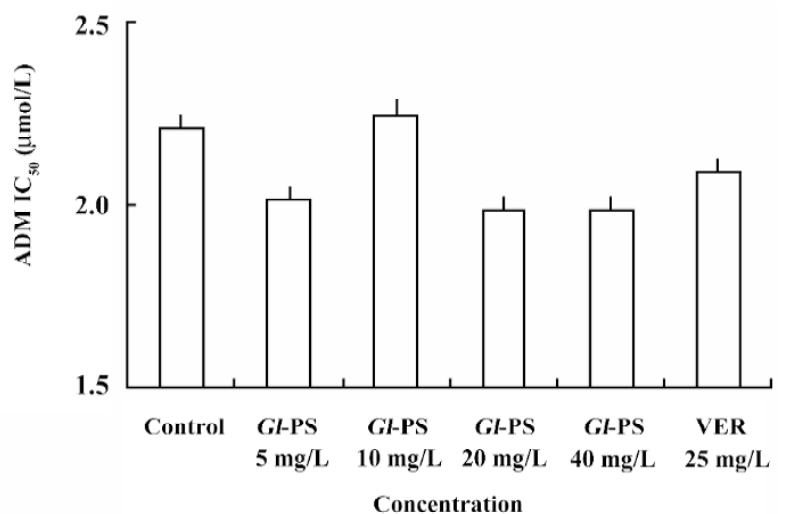

B

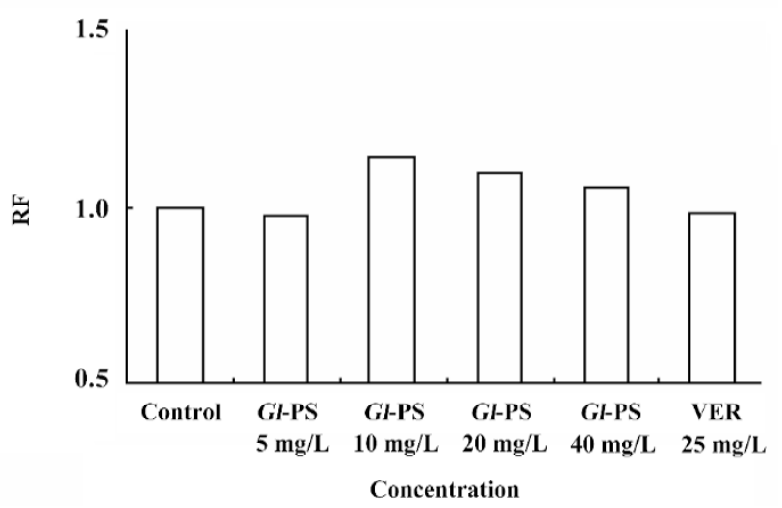

Figure 1. (A). Effects of $G l$-PS on sensitivities of K562 cells to ADM. (B). Reverse index of drug resistance by $G l$-PS in K562 cell. Cells were incubated in 96 -well plates $\left(1.0 \times 10^{5} /\right.$ well $)$, in $100 \mu \mathrm{L}$ medium containing ADM and $G l$-PS $(5,10,20$ and $40 \mathrm{mg} / \mathrm{L})$ were added. VER was used as a positive control. After $44 \mathrm{~h}$ incubation, $20 \mu \mathrm{L}$ MTT ( $5 \mathrm{~g} / \mathrm{L}$ in PBS) were added. After $4 \mathrm{~h}$ inhibition, the absorbance at $570 \mathrm{~nm}$ was determined using an enzyme-linked immunsorbent assay multikan reader. $n=4$. VER, verapamil; RF, reversing factor.

ADM, the K562/ADM cells removed most of their intracellular ADM content during 90 min incubation in the medium alone; the intracellular ADM concentration was down to 2.39-folds that of the K562 cells. With the existence of $\mathrm{Gl}$-PS, the efflux of ADM in the K562/ADM cells can be modulated. A total of $10 \mathrm{mg} / \mathrm{L} G l$-PS caused a 2.4-fold increase in ADM accumulation in the K562/ADM, cells and $50 \mathrm{mg} / \mathrm{L}$ Gl-PS caused a 2.2-fold increase (Figure 4).

Effect of $G l$-PS on expression of P-gp in K562 and K562/ ADM cell lines To evaluate the P-gp expression level, the K562/ADM cells were analyzed with the anti-P-gp monoclonal antibody. VER was used as the positive control. As shown in Figure 5, the expression rates of P-gp were 78.54\% in untreated K562/ADM cells, and 36.73\% and $51.73 \%$ in 10 and $50 \mathrm{mg} / \mathrm{L} \mathrm{Gl}$-PS-treated K562/ADM cells, respectively.
A

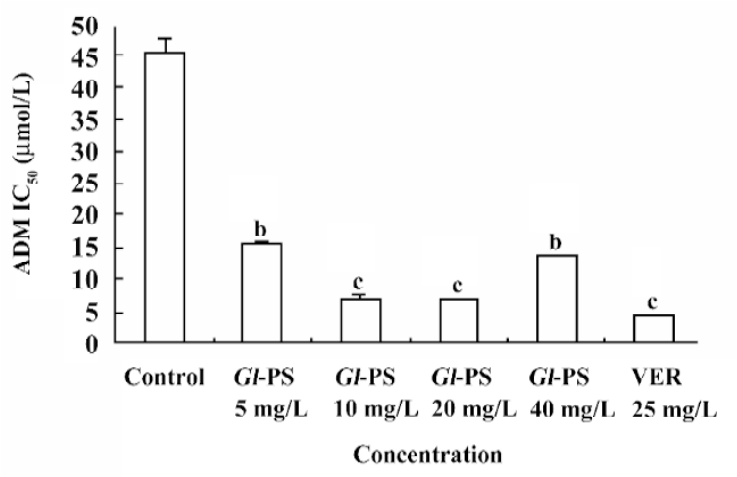

B

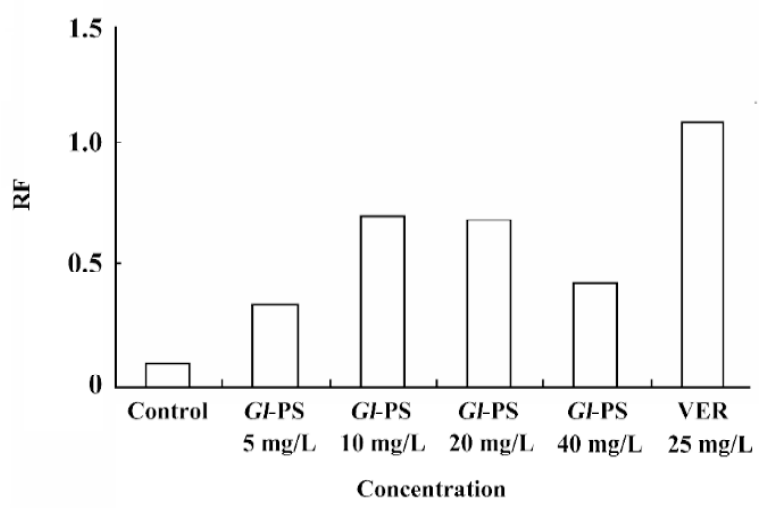

Figure 2. (A). Effects of $G l$-PS on sensitivities of K562/ADM cells to ADM. (B). Reverse index of drug resistance by $G l$-PS in K562/ ADM cell. Mean \pm SD. ${ }^{\mathrm{b}} P<0.05,{ }^{\mathrm{c}} P<0.01 v s$ control group. Cells were incubated in 96 -well plates $\left(1.0 \times 10^{5} /\right.$ well $)$, in $100 \mu \mathrm{L}$ medium containing ADM and $G l$-PS (5, 10, 20 and $40 \mathrm{mg} / \mathrm{L})$ were added. VER was used as a positive control. After $44 \mathrm{~h}$ incubation, $20 \mu \mathrm{L}$ MTT (5 g/ $\mathrm{L}$ in PBS) were added. After $4 \mathrm{~h}$ inhibition, the absorbance at $570 \mathrm{~nm}$ was determined using an enzyme-linked immunsorbent assay multikan reader. $n=4$. VER, verapamil; $\mathrm{RF}$, reversing factor.

The VER group showed a level at $60.09 \%$. So we can conclude that after treatment with $\mathrm{Gl}$-PS, the expression rate of P-gp was reduced distinctly (Figure 5).

$G l$-PS downregulating MDR-1 and MRP1 gene expression in MDR K562/ADM cells The K562/ADM cells were shown by RT-PCR to express MDR-1 and MRP genes at a rate of $56.58 \%$ and $37.59 \%$, respectively. Neither of the genes was detectable in the K562 cells (data not shown). Treatment with $G l$-PS (10 mg/L) for $24 \mathrm{~h}$ led to the downregulation of MDR-1 and MRP mRNA expression in MDR cells. The levels of MDR-1 and MRP1 mRNA nearly disappeared to a level of $8.89 \%$ and $7.95 \%$, respectively; $G l-\mathrm{PS}(50 \mathrm{mg} / \mathrm{L})$ was also detected. The expression levels of MDR-1 and MRP-1 were also greatly reduced to approximately $11.12 \%$ and $10.05 \%$, respectively (Figure 6). 


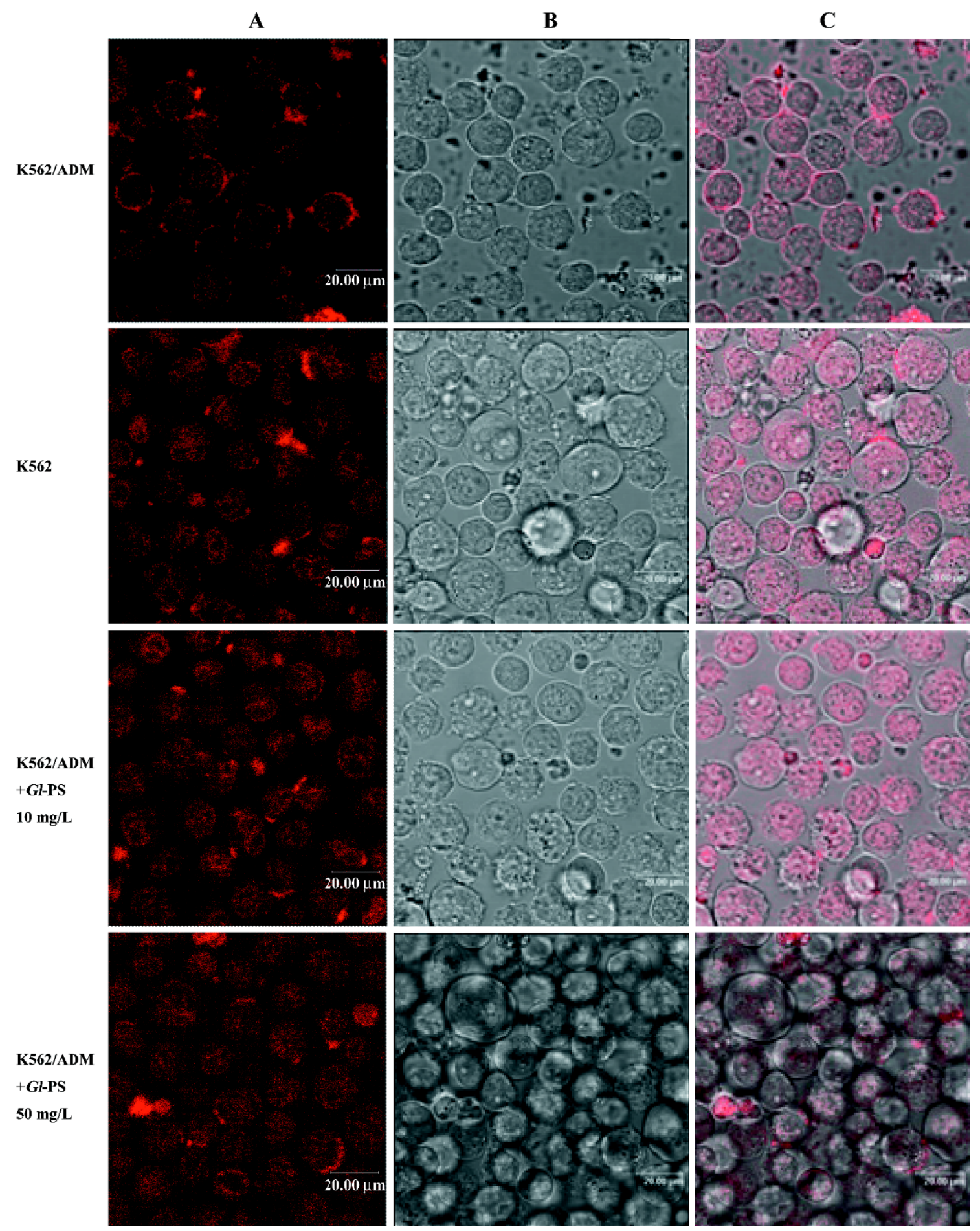

Figure 3. Digital images of ADM accumulation in K562/ADM, K562, K562/ADM plus $10 \mathrm{mg} / \mathrm{L}$ Gl-PS and K562/A plus $50 \mathrm{mg} / \mathrm{L}$ Gl-PS. Image A show ADM auto-fluorescence. Image B was taken at normal microscopy. Image C was generated from A and B.

\section{Discussion}

Nearly $50 \%$ of human cancers are either completely re- sistant to chemotherapy or respond to chemotherapy only transiently, after which they are no longer affected by common anticancer drugs. This phenomenon is referred to as 

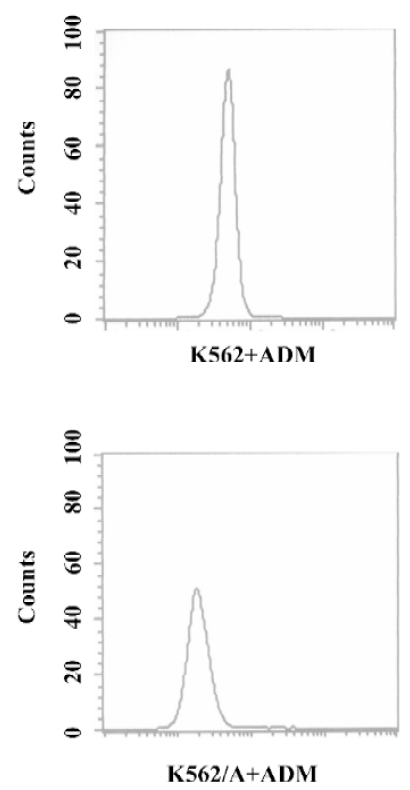
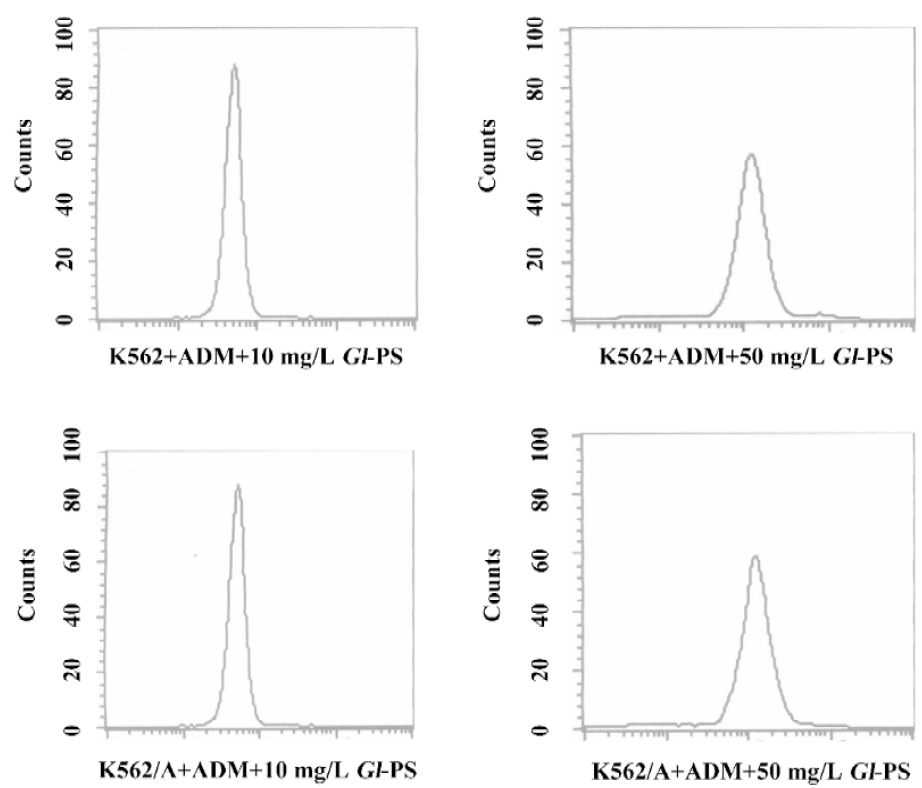

Figure 4. Effect of $G l$-PS on ADM efflux in K562 and K562/A cells. ADM efflux was determined by flow cytometry in presence and absence of $G l$-PS at $10 \mathrm{mg} / \mathrm{L}$ and $50 \mathrm{mg} / \mathrm{L}$. Intracellular ADM concentration was measured as log-scale fluorescence intensity (FL2). Efflux in presence and absence of each $\mathrm{Gl}$-PS was compared by the Kolmogorov-Smirnov statistic, expressed as a D-value.
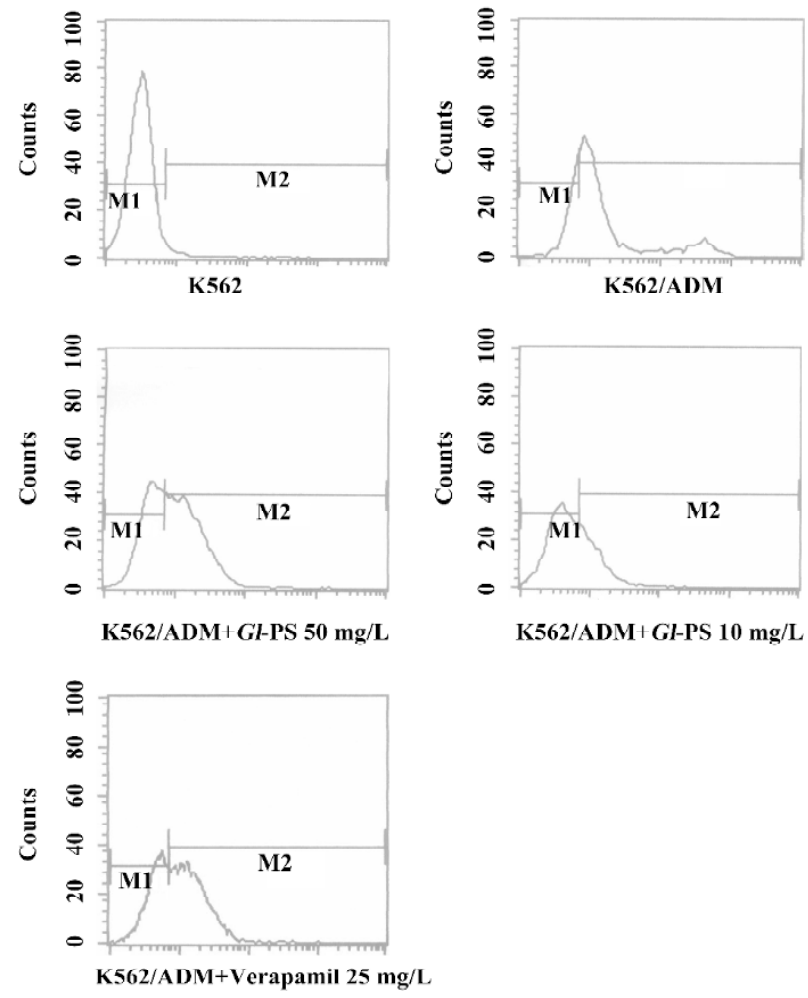

Figure 5. Effect of $G l$-PS on P-gp expression in K562 and K562/ ADM cells. P-gp expression level was determined by flow cytometry in presence and absence of $G l$-PS at $10 \mathrm{mg} / \mathrm{L}$ and $50 \mathrm{mg} / \mathrm{L}$. P-gp expression level was shown as log-scale fluorescence intensity and compared by the Kolmogorov-Smirnov statistic.
Table 1. Oligonucleotide primers for MDR-1, MRP1, and $\beta$-actin.

Oligonucleotide primer

MDR-1

5'-CTGGTGTTTGGAGAAATGACAG-3' (sense) 5'-CCCAGTGAAAAATGTTGCCATTGAC-3' (antisense)

MRP1

5'-TCTCTCCCGACATGACCGAGG-3' (sense) 5'-CCAGGAATATGCCCCGACTTC-3' (antisense)

$\beta$-actin

5'-ACCCCCACTGAAAAAGATGA-3' (sense) 5'-ATCTTCAAACCTCCATGATG-3' (antisense)

MDR and is inherently expressed by some tumor types, while others acquire MDR after exposure to chemotherapy treatment. We are actively investigating the mechanisms involved in MDR, as well as developing therapeutic strategies to circumvent these resistance mechanisms. We evaluated tumor cells for MDR related to several resistance processes and have made significant breakthroughs in reversing MDR mediated by the drug efflux pump P-glycoprotein. Phenotypic and functional analyses of MDR mechanisms presented in human tumor specimens are also being conducted in order to relate specific MDR mechanisms with resistance to chemotherapy in specific tumor types. 

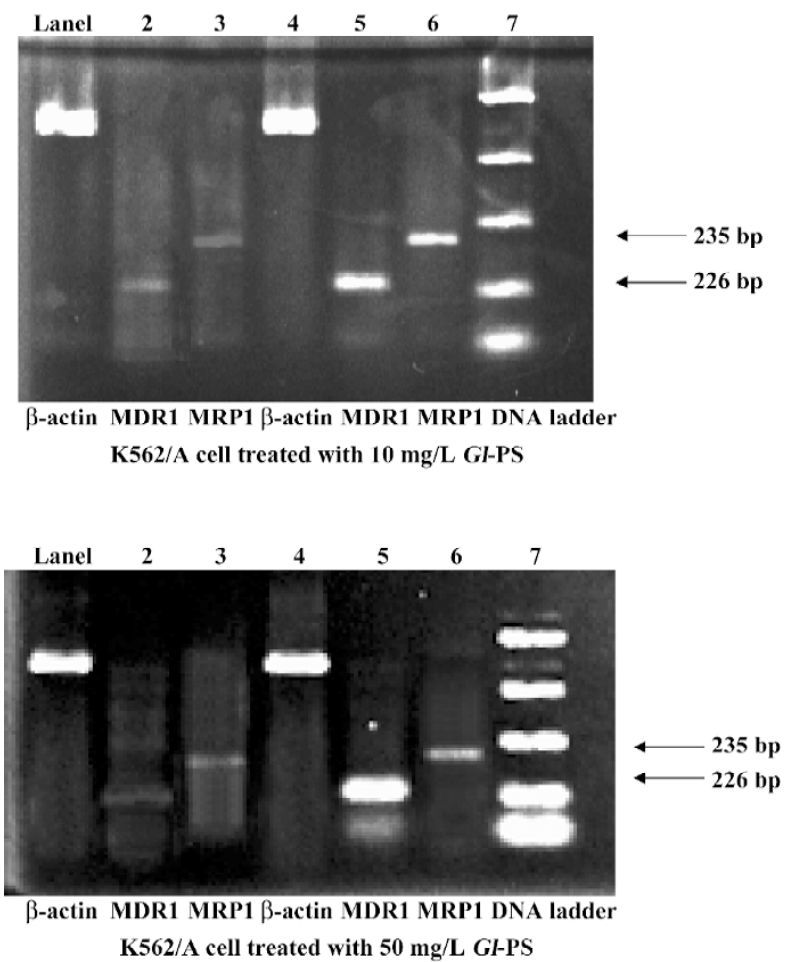

Figure 6. MDR 1 and MRP1 transcript determined by RT-PCR. RTPCR analysis of total RNA obtained from K562/A and K562/A plus 10 $\mathrm{mg} / \mathrm{L}$ (top) or $50 \mathrm{mg} / \mathrm{L} G l$-PS (bottom). The primers for human mdr- 1 and mrp- 1 and the control housekeeper gene $\beta$-actin are shown in Table 1. Lanes 1, 2 and 3, K562/A cells with Gl-PS. Lanes 4, 5 and 6 , K562/A cells without $G l$-PS, respectively. Lane 7 is the DNA ladder.

MDR has been explained by the overexpression of a family of ATP-binding cassette (ABC) transporters called MDR proteins. $\mathrm{ABC}$ transporters are an ever-increasing family of proteins $^{[25]}$. The human MDR-1 gene encoding the MDR transporter (P-gp-170) belongs to the ABC transporter superfamily, of which there are 9 members. Uptake and/or efflux of isotope-labeled drugs or rhodamine123 are frequently used for the functional assay of P-gp-170 in tumor cells. Several classes of MDR modulators that inhibit P-gpmediated efflux have been identified. P-gp and MRP1 are constitutively expressed at many tumor cell lines and pump drugs out of cells. Such a spatial distribution of this efflux transporter has defined it as a functionally-important element in reducing the effects of antitumor drugs.

The Gl-PS, a traditional Chinese medicine, has been proven to be effective in tumor therapy. Our previous research proved that $G l$-PS have antitumor activity both in vivo and in vitro ${ }^{[24]}$. There have been many studies on the antitumor activity of $G l$-PS and their possible mechanisms, and many exciting results have been obtained. However, due to its complexity in structure, the mechanisms by which the $G l$-PS act in the cells are unclear. $G l$-PS have low toxicity in humans, which is in contrast to other drugs, such as VRPL, that leads to $40 \%$ lethality in mice at $150 \mathrm{mg} / \mathrm{kg}$ per day for $3 \mathrm{~d}$. The remarkably low toxicity of $G l$-PS coupled with their potent MDR-reversing activity as demonstrated earlier, renders them appropriate for further study and development.

In the present study, we sought to use several different, but complementary experimental approaches to examine whether $G l$-PS can reverse MDR. K562 cells repelling ADM are the best models for MDR research and have been selected in many previous studies ${ }^{[26]}$ We have validated that this cell line really has high-level expression of P-gp and MRP1 (unpublished data). Depending on P-gp and MRP1 activity, ADM was pumped out of the K562/ADM cells and formed a ring adhering to the cells. The condition in the K562 cells was different: ADM was distributed into the cells at a high concentration. After incubating the K562/ADM cells with both $\mathrm{ADM}$ and $G l$-PS, the ADM-accumulating rings disappeared and the distribution conditions were greatly similar to that of the K562 cells. So we can conclude that $G l$-PS has the ability to downregulate the effect of P-gp by an unknown mechanism. However, we chose ADM as the antitumor drug because of its auto-fluorescence that can be easily assayed in the experiment. It is interesting that $G l$-PS has a prominent effect on reversing MDR. The cytotoxity assay results indicated that proper concentrations of $G l$-PS can reduce the viability of K562/ADM cells in ADM. The results of the confocal assay supported this conclusion and showed that the rate of pumping drugs out of K562/ADM cells was also reduced. To determine whether $G l$-PS could downregulate the P-gp and MRP1 functional expression in the K562/ADM cells, we tested the P-gp expression level on the cell membrane using the flow cytometric assay. Our results confirmed the hypothesis that the P-gp expression was downregulated under $G l$-PS treatment. Furthermore, the results of the RTPCR experiments confirmed that MRP1 and P-gp were significantly inhibited at the mRNA level. Our studies suggest that $G l$-PS can reverse MDR by downregulating the expressions of P-gp and MRP1.

\section{Acknowledgements}

Gl-PS was kindly provided by Prof Shu-qian LIN and Saizhen WANG of the Fuzhou Institute of Green Valley BioPharm Technology, Fuzhou, China.

\section{References}

1 Goldstein LJ. MDR1 gene expression in solid tumors. Eur J Cancer 1996; 32: 1039-50.

2 Jonker JW, Buitelaar M, Wagenaar E. The breast cancer resistance protein protects against a major chlorophy11-derived di- 
etary phototoxin and protoporphyria. Proc Natl Acal Sci USA 2002; 99: 15649-54.

3 Johnstone RW, Ruefli AA, Lowe SW. Apoptosis: a line between cancer genetics and chemotherapy. Cell 2002; 108: 153-64.

4 Shen DW, Cardarelli C, Hwang J, Cornwell M, Richert N, Ishii S, et al. Multiple drug-resistant human $\mathrm{KB}$ carcinoma cells independently selected for high-level resistance to colchicines, adriamycin, or vinblastine show changes in expression of specific proteins. J Biol Chem 1986; 261: 7762-70.

5 Tan B, Piwnica WD, Rater L. Multidrug resistance transporters and modulation. Curr Opin Oncol 2000; 12: 450-8.

6 Sharom FJ, Yu X, Lu P, Liu P, Chu JW, Szabo K, et al. Interaction of the P-glycoprotein multidrug transporter (MDR1) with high affinity peptide chemosensitizers in isolated membranes, reconstituted systems and intact cells. Biochem Pharmacol 2003; 58: 571-86.

7 Sikic BI. Modulation of multidrug resistance: a paradigm for translational clinical research. Oncology 1999; 13: 183-7.

8 Hu YP, Pourquier P, Doignon F, Crouzet M, Robert J. Effects of modulators of multidrug resistance on the expression of the MDR1 Gene on human KB cells in culture. Anticancer Drugs 1996; 7: 738-44.

9 Tsuruo T, Iida H, Tsukagoshi S, Sakurai Y. Overcoming of vincristineresistance in P388 leukemia in vivo and in vitro through enhancedcytotoxicity of vincristine and vinblastine by verapamil. Cancer Res 1981; 41: 1967-72.

10 Lei LS, Lin ZB. Effects of Ganoderma polysaccharides on the activity of DNA polymerase in spleenocytes and immune function in aged mice. Acta Pharm Sin 1993; 28: 577-82.

11 Zhang QH, Lin ZB. The antitumor avtivity of Ganoderma lucidum (Curt:Fr.) P. Karst. (LingZhi) (Aphyllophoromycetideae) polysaccharides is related to tumor necrosis factor- $\alpha$ and interferon- $\gamma$. Int J Med Mushroom 1999; 1: 207-15.

12 Lin ZB. Anti-aging activities of Ganoderma lucidum. In Lin ZB, editor. 2007. Modern research of Ganoderma.3rd ed. Beijing: Beijing Medical University Publishing House; 2007. p 241-2.

13 Chen HS, Lin $\mathrm{CH}$, Wong $\mathrm{CH}$. Studies on the immuno-modulating and anti-tumor activities of Ganoderma lucidum polysaccharides. Bioorg Med Chem 2004; 12: 5595-601.

14 Zhang QH, Lin ZB. Study on antitumor activity and mechanism of Ganoderma polysaccharides B. Chin J Integrated Tradit West
Med 1999; 19: 544-7.

15 Zhang QH, Yu D H, Lin ZB. Study on the antitumor mechanism of ganoderma lucidum extract (gle) by serologic pharmacological method. J Beijing Med Univ 2000; 32: 210-3.

$16 \mathrm{Hu}$ YH, Lin ZB, He YQ, Zhao CJ. Polysaccharides isolated from mycelia of ganoderma lucidum induced on hl-60 cell apoptosis by enhancing macrophage activity. Chin Pharmacol Bull 1999; 15: 27-30.

17 Sliva D, Labarrere C, Slivova V, Sedlak M, Lloyd FPJ, Ho NW. Ganoderma lucidum suppresses motility of highly invasive breast and prostate cancer cells. Biochem Biophy Res Commun 2002; 298: 603-12.

18 Lei LS, Lin ZB, Chen Q, Li R Z, He YQ. Antagonistic effect of ganoderma lucidum polysaccharides on the immunosuppressive response induced by ciclosporin a, hydrocortisone and antitumor agents. Chin J Pharmacol Toxicol 1994; 7: 183-5.

19 Li WD, Han Q, Lin ZB. Antagonization of ganoderma polysaccharides and lentinan on bearing sarcoma 180 mice's immunosuppressive effect induced by cyclophosphamide. Chin J Integt Trad West Med 2001; 21 (Suppl): 101-4.

20 Lin ZB, Zhang HN. Anti-tumor and immunoregulatory activities of Ganoderma lucidum and its possible mechanisms. Acta Pharmacol Sin 2004; 25: 1387-95.

21 Alley MC, Scudiero DA, Monks A. Feasibility of drug screening with panels of human tumour cell lines using a microculture tetrazolium assay. Cancer Res 1988; 48: 589-601.

22 Barhoumi R, Bailey RH, Burghardt RC. Kinetic analysis of glutathione in anchored cells with monochlorobimane. Cytometry 1995; 19: 226-34.

23 Minderman H, Suvannasankha A, O'Loughlin KL, Scheffer GL, Scheper RJ, Robey RW, et al. Flow cytometric analysis of breast cancer resistance protein expression and function. Cytometry 2002; 48: 59-65.

24 Cao QZ, Lin ZB. Antitumor and anti-angiogenic activity of Ganoderma lucidum polysaccharides peptide. Acta Pharmacol Sin 2004; 25: 833-8.

25 Jeanette $\mathrm{W}$, Jan $\mathrm{CD}$. Involvement of multidrug resistance proteins (P-gp) and in the modulation of glucocorticoid response. J Steroid Biochem Mol Biol 2002; 82: 277-88.

26 Miao ZH, Ding J. Transcription factor c-Jun activation represses $m d r-1$ gene expression. Cancer Res 2003; 63: 4527-32. 